\title{
Programa de Sensibilização Sustentável do Turismo: uma proposta para envolvimento e participação de comunidades locais ${ }^{1}$
}

\author{
Sustainable Tourism Sensitization:
}

a program to engage and promote the participation of local communities

\author{
Frederico Yuri Hanai ${ }^{2}$ \\ Evaldo Luiz Gaeta Espíndola ${ }^{3}$
}

\begin{abstract}
Resumo
Os esforços recentes de desenvolvimento do turismo têm buscado incorporar os postulados de sustentabilidade, procurando assegurar a promoção e a produção de benefícios direcionados às comunidades locais, requerendo sua participação neste processo. $\mathrm{O}$ objetivo do presente trabalho é apresentar um exemplo de aplicação de programa de sensibilização turística (na região sul do estado de Minas Gerais, Brasil), discorrendo-se sobre as concepções, procedimentos adotados, resultados e recomendações na proposição e implementação de programas de sensibilização turística em destinos turísticos. O programa de sensibilização turística constituiu-se numa valiosa forma de sensibilizar a população local sobre a sustentabilidade do turismo e permitiu: aumentar sua capacidade de participação e de organização; fortalecer sua capacidade de argumentação frente a outros interlocutores; incentivar o seu envolvimento e potencializar sua atuação de forma conjunta e integrada nas ações de desenvolvimento turístico local.
\end{abstract}

Palavras-chave: sensibilização turística; turismo sustentável; participação; população local; comunidade local.

\begin{abstract}
Recent efforts to develop tourism have taken into account principles of sustainability in an attempt to ensure the generation and promotion of benefits for local communities, a process which requires the participation of community members. This study aims to report a application of sensitization program in tourism on a case in southern Minas Gerais state in Brazil, and to address concepts, procedures and recommendations related to sensitization
\end{abstract}

\footnotetext{
${ }^{1}$ Agradecemos ao Conselho Nacional de Desenvolvimento Científico e Tecnológico (CNPq) pela concessão da bolsa de doutorado, viabilizando a dedicação integral e exclusiva à realização da presente pesquisa e ao Programa Petrobras Ambiental pelo financiamento do Projeto Mogi-Guaçu que propiciou a realização do presente trabalho.

${ }^{2}$ Professor Adjunto (Doutor) da Universidade Federal de São Carlos - UFSCar. Email: fredyuri@ufscar.br.

${ }^{3}$ Professor Livre Docente - Escola de Engenharia de São Carlos - EESC - Universidade de São Paulo - USP. Email: elgaeta@sc.usp.br.
} 
programs in tourism. The sensitization program in tourism represents a valuable element to raise the local population's awareness of sustainability in tourism and has made it possible: to enhance the community's ability to participate and self-organize; to build on the members' ability to engage in discussions with other interlocutors; to encourage participation and potentize integrated and collaborative actions towards the development of local tourism.

Keywords: tourism sensitization; sustainable tourism; participation; local population; local community.

\section{Introdução}

As aspirações de sustentabilidade conduzem a novas idéias de pensar, abordar e agir em processos e fenômenos de desenvolvimento, inserindo e incorporando os princípios éticos e propósitos do desenvolvimento sustentável em sua performance. Os diversos fatores e critérios relacionados ao conceito de sustentabilidade requerem novas concepções de planejamento num sentido mais amplo, que implica em reconhecer os problemas sociais, a diversidade cultural, a dinâmica ambiental, as peculiaridades locais e as suas especificidades, num processo de transformação socioambiental.

Algumas metodologias atuais de planejamento visando a sustentabilidade têm se preocupado com a escala local, inserindo abordagens de participação e envolvimento da comunidade, procurando assegurar a produção de benefícios locais, assim como a geração de melhorias na sua qualidade de vida e bem-estar social.

Segundo Petersen e Romano (1999), projetos bem sucedidos de desenvolvimento estão, em geral, associados às condições primordiais de participação da sociedade civil na elaboração e implementação de planos, programas e ações inovadoras, e enfoque local no processo de desenvolvimento.

Assim, a busca e a eficácia da sustentabilidade local devem enfatizar precisamente as propostas que permitam a verdadeira inclusão dos atores da comunidade, envolvidos num mesmo processo com a determinação e capacidade para realizá-las (MARTÍNEZ e HIRABAYASHI, 2003; RANAURO, 2004).

Também nos estudos de turismo são frequentes os discursos sobre a participação da comunidade local com a colaboração individual e ativa no processo de desenvolvimento 
turístico. "A participação dos vários atores sociais da comunidade é um dos elementos mais importantes para a realização do desenvolvimento do turismo sustentável” (KO, 2005, p.439). Entretanto, são poucos os trabalhos e as iniciativas que se direcionam ao empenho de sensibiliizar e educar turisticamente os residentes locais, assim como de promover e/ou criar espaços para a sua participação efetiva nas discussões e definições do desenvolvimento turístico local.

Em alguns casos, quando isso se faz (disponibilidade de abertura e condições para o envolvimento da sociedade local), esbarra-se em situações de participação ilusória dos moradores locais, que ludibriados pelas possibilidades e oportunidades do desenvolvimento turístico, aceitam passivamente as decisões tomadas e direcionadas a interesses de grupos individuais, que nem sempre constituem-se nos benefícios coletivos. Tais situações devem ser evitadas, por meio de oportunidades de atuação ativa da comunidade local, propiciadas pela sua sensibilização e conhecimento sobre o fenômeno turístico.

No entanto, a efetiva participação das comunidades anfitriãs requer a compreensão do processo de desenvolvimento do turismo, que somente é possível se houver a necessária incorporação de conhecimentos básicos sobre turismo e um maior esclarecimento dos fenômenos associados à atividade turística.

Constata-se, portanto, que o esforço em sensibilização da sociedade para o turismo sustentável é primordial para a construção de novos paradigmas do desenvolvimento turístico, envolvendo além da capacitação das comunidades locais, o investimento nas potencialidades regionais e a discussão dos riscos e benefícios que o turismo pode trazer para um determinado destino (IRVING et al, 2005).

Comunidades anfitriãs, esclarecidas e conscientes de sua responsabilidade para o sucesso do desenvolvimento turístico, podem participar e se envolver, de maneira ativa e efetiva, nos processos decisórios locais, permitindo o seu posicionamento de forma crítica, a fim de valorizar a sua identidade e o seu interesse local pelo turismo, fortalecendo os princípios sustentáveis do desenvolvimento.

O objetivo do presente trabalho é apresentar um exemplo de aplicação de programa de sensibilização turística na região sul do estado de Minas Gerais, Brasil, discorrendo-se sobre 
as concepções, procedimentos adotados, resultados e recomendações na proposição e implementação de programas de sensibilização turística em destinos turísticos.

\section{Turismo Sustentável e a Participação da Sociedade}

De acordo com o artigo $4^{\circ}$ da Carta de Lanzarote (CONFERÊNCIA MUNDIAL DE TURISMO SOSTENIBLE, 1995), a contribuição ativa do turismo ao desenvolvimento sustentável pressupõe necessariamente a solidariedade, o respeito mútuo e a participação de todos os atores, tanto públicos com privados, envolvidos no processo de desenvolvimento.

O desafio da sustentabilidade em destinos turísticos é urgente e requer o compromisso institucional das autoridades locais, assim como a colaboração ativa dos atores individuais que atuam nos destinos (YUNIS, 2002). "Não há como pensar em sustentabilidade sem a contribuição equitativa das comunidades e seus saberes" (RANAURO, 2004, p. 27).

A lógica do turismo sustentável requer um processo eminentemente participativo, cujo êxito depende da capacidade de envolver a sociedade, que é, sobretudo, o protagonista do processo de desenvolvimento turístico (CHOI e SIRAKAYA, 2005; SÁNCHEZ RIVERO e PULIDO FERNÁNDEZ, 2008).

O desenvolvimento sustentável do turismo deve ser planejado e administrado pelos atores sociais de uma comunidade (CHOI e SIRAKAYA, 2006). De forma particular, os governantes locais devem solicitar a seus residentes ampla e direta participação para que possam influenciar nas tomadas de decisão e garantir a todos os atores sociais uma distribuição justa de benefícios.

Entretanto, a participação das comunidades não deve ser entendida como um processo passivo de envolvimento entre as pessoas, ou num monólogo assistido e concordado, que se exerce parcialmente ou em certos setores da vida social ou do processo educacional (RANAURO, 2004). A participação relaciona-se ao poder efetivo de decisão e implica no envolvimento ativo em todas as instâncias, e em todos os domínios, visando resgatar e valorizar os saberes locais.

Alguns pesquisadores, planejadores, tomadores de decisão e representantes do setor turístico têm reclamado do processo de planejamento participativo, considerando-o improdutivo com 
dispêndio de tempo (SWARBROOKE, 2000). Mas, Boothroyd (1986) argumenta que apesar do processo participativo consumir mais tempo do que outros métodos, os resultados provenientes possuem maior probabilidade de obter sucesso.

Boothroyd (1986) listou cinco benefícios do processo de desenvolvimento participativo, a saber: melhoria das bases de informação; garantia de que os residentes locais (influenciados pelas decisões) foram consultados e estão mais bem informados; criação de senso de compreensão comum e entendimento coletivo; estabelecimento de um amplo compromisso para decisões; e melhoria do suporte em direção do desenvolvimento do turismo.

A efetiva participação das comunidades locais no processo de planejamento e gestão da atividade turística é essencial e imprescindível, pois a população local é conhecedora e vivencia a sua realidade imediata, sendo capaz de identificar problemas e necessidades, avaliar alternativas, desenvolver estratégias para proteção e/ou valorização de patrimônios naturais e culturais, buscando soluções para os problemas identificados e sugerindo caminhos que levem à melhoria da qualidade de vida, ao fortalecimento da cultura local e ao bem-estar social (IRVING et al., 2005).

\section{A Importância e a Necessidade de Programas de Sensibilização Turística}

Os princípios do turismo sustentável prescrevem o envolvimento, a participação e a mobilização da população local no processo de desenvolvimento turístico. Esta abordagem participativa só pode ser concretizada se a sociedade local incorporar os conceitos básicos da sustentabilidade do turismo e possuir o discernimento e a compreensão dos diversos aspectos envolvidos no processo de seu desenvolvimento.

A inexistência da consciência turística da comunidade local e de sua compreensão básica sobre o fenômeno turístico numa localidade pode ocasionar:

- Desinteresse da comunidade no processo participativo de desenvolvimento turístico local;

- Visão depreciativa do turismo e atitude de resistência e receio ao seu desenvolvimento, compromentendo a imagem do destino turístico;

- Frustrações locais e perda da credibilidade no desenvolvimento turístico; 
- Falta de preparação para atuação direta ou indireta no turismo, refletindo na qualidade dos serviços e da receptividade dos turistas;

- Desconsideração dos verdadeiros interesses comunitários da sociedade local.

Estas situações são complicadas de serem revertidas, exigindo esforços bem maiores do que a elaboração e aplicação de um programa de sensibilização turística para a comunidade local.

A sensibilização turística da população local torna-se uma etapa fundamental do processo de planejamento e organização do turismo, possibilitando o sucesso da implementação de planos e projetos de turismo. Além disso, permite que a própria comunidade consiga, por consciência própria, optar pelo tipo de turismo desejável, definindo os rumos e o direcionamento dos procedimentos para o desenvolvimento da sociedade local.

No Brasil, com o intuito de promover o desenvolvimento das regiões turísticas, o Ministério do Turismo elaborou documentos técnico-orientadores para a implementação do Programa de Regionalização do Turismo (BRASIL, 2004a, 2004b). Em seu caderno do módulo operacional de sensibilização, o Ministério do Turismo (BRASIL, 2007) define que sensibilizar é oferecer, às pessoas da comunidade ou da região, os meios e os procedimentos que as façam perceber novas possibilidades e lhes permitam enfrentar as mudanças e as transformações necessárias quando se adota uma nova postura frente ao turismo. "Significa, na prática, convencer as pessoas da comunidade de que sua organização e seu envolvimento são condições essenciais para o fortalecimento de sua região" (BRASIL, 2007, p.15, grifo nosso).

Entretanto, o intuito a que se refere à sensibilização citada neste documento difere da abordagem considerada na concepção do presente trabalho, pois a sensibilização da comunidade local tem a intenção de esclarecimento e não de convencimento sobre o turismo, no sentido de torná-las aptas à tomada de suas próprias decisões sobre o futuro do desenvolvimento turístico.

A sensibilização turística prepara a comunidade para entender o processo do desenvolvimento do turismo e, assim, cria oportunidades aos residentes de envolverem-se ativamente com a atividade (OLIVEIRA, 2002), viabilizando a consecução de ações conjuntas e integradas e a concretização de objetivos comuns e congruentes. 
McCool, Moisey e Nickerson (2001) realizaram uma pesquisa no estado de Montana (EUA) envolvendo 108 membros do setor privado do turismo (líderes e representantes do setor turístico) com objetivo de investigar a relação entre o conceito de sustentabilidade e o turismo, e de que forma a sustentabilidade do turismo deve ser medida. Dos resultados obtidos, os autores concluíram que o conceito de sustentabilidade existente na concepção dos membros entrevistados é vago e incapaz de ser traduzido adequadamente nas políticas específicas, nas ações ou nos indicadores de sustentabilidade. Os dados mostraram uma desconexão entre as prioridades a serem sustentadas pelo turismo e os indicadores que deveriam medir os progressos em direção a esses objetivos prioritários.

O trabalho realizado por McCool, Moisey e Nickerson (2001) mostrou que a falta de consistência dos resultados refletiu a confusão do significado de sustentabilidade do turismo presente na concepção dos respondentes (líderes e representantes entrevistados). Esta confusão existe não somente nos envolvidos com setor turístico, mas provavelmente nos grupos de gestores e residentes locais. Os resultados obtidos sugerem implicações para o desenvolvimento do turismo: se o turismo é visto como uma ferramenta de desenvolvimento para alcançar a sustentabilidade, deveria haver concordância entre os grupos (setor privado, gestores e residentes locais) no que é ser sustentável, assim como nos caminhos apropriados para este objetivo (McCOOL, MOISEY E NICKERSON, 2001).

Este caso ilustra a importância e a necessidade da consciência e da compreensão da sociedade sobre a sustentabilidade do turismo, que direcionam as metas e ações para o desenvolvimento sustentável local. A compreensão da sociedade e o estabelecimento da consciência comum sobre a sustentabilidade do turismo podem ser viabilizados pelos programas de sensibilização turística.

Além disso, a benevolência e a cooperação de comunidades receptoras no processo de desenvolvimento turístico são elementos fundamentais no sucesso do destino turístico, pois sua receptividade influencia fortemente na atração e satisfação turística dos visitantes.

O envolvimento, a mobilização e a participação desejáveis da população local nos processos de planejamento, organização e desenvolvimento sustentável do turismo podem ser viabilizados por meio de programas de sensibilização e educação turísticas, que devem ser elaborados e executados em função das características socioculturais locais. 


\section{Os Programas de Sensibilização Sustentável do Turismo}

Os programas de sensibilização turística visam promover aos residentes de destinos turísticos a elucidação das necessidades, prioridades e aspectos essenciais do planejamento e desenvolvimento do turismo sustentável, ressaltando a importância da sua participação e atuação social neste processo.

A realização dos programas de sensibilização turística não tem o intuito de convencer a sociedade local a considerar o turismo como a única opção ideal para a solução de todos os problemas e para melhorar as condições ambientais e socioeconômicas da comunidade.

Os programas de sensibilização turística devem apresentar à sociedade local, as informações e os conteúdos sobre as oportunidades e também sobre os possíveis riscos que o desenvolvimento turístico pode provocar na localidade. Além disso, a sensibilização turística deve preparar a comunidade para assumir as responsabilidades coletivas da atividade turística, a fim de se evitar os possíveis impactos negativos e maximizar os potenciais benefícios advindos da atividade turística.

Os programas de sensibilização turística devem ser elaborados de forma sistemática, com base no estabelecimento dos seus objetivos, na determinação dos grupos-alvo, com especificação das técnicas de sensibilização a serem utilizadas.

As técnicas básicas normalmente empregadas nos programas de sensibilização pública são (ORGANIZAÇÃO MUNDIAL DE TURISMO, 2003; BRASIL, 2007): programas de rádio regulares; programas locais de televisão; artigos de jornais; pôsteres, planfletos, livretos; educação para o turismo em sistema escolar; reuniões da comunidade sobre turismo; publicação de periódicos locais; seminários e conferências públicas.

Os programas de sensibilização turística consistem num importante veículo multiplicador, irradiador e disseminador dos conceitos turísticos, incentivando e mobilizando a participação da sociedade local no processo de desenvolvimento local. 


\section{O Método Empregado}

O presente trabalho descreve os procedimentos metodológicos adotados para o envolvimento e a participação da sociedade local durante a realização de ações de desenvolvimento sustentável do turismo na região sul do estado de Minas Gerais, Brasil.

Esta região possui características geográficas, paisagísticas, climáticas e atributos naturais e rurais potencialmente turísticos. A região montanhosa, com relevo bastante acidentado e entrecortado por vales, aliada às particularidades da hidrografia local formam cenários paisagísticos com serras e inúmeras cachoeiras, de atratividade para o desenvolvimento turístico.

Além de oferecer opções de atrativos naturais e diversos patrimônios históricos, arquitetônicos, culturais e rurais existentes, a região possui um importante centro industrial de produção de tecelagens e confecções, consolidando-se num pólo atrativo de comércio de malhas do país.

Em alguns municípios desta região, já existem empreendimentos turísticos e arranjos institucionais de organização e gestão do turismo, subsidiados pela atuação de dois Circuitos Turísticos do estado: o Circuito Serras Verdes do Sul de Minas e o Circuito das Malhas, que têm promovido o desenvolvimento do turismo na região.

A seguir são apresentados os procedimentos adotados na elaboração e aplicação do programa de sensibilização turística, visando o envolvimento e a participação da comunidade local nas ações de planejamento, organização e estruturação do desenvolvimento do turismo:

1) Identificação do perfil socioeconômico e cultural da população local (entrevistas com a população local);

2) Preparação do conteúdo e elaboração de materiais didáticos e informativos para o programa de sensibilização turística;

3) Aplicação do programa de sensibilização turística em meios de comunicação (spots para veiculação em rádios, entrevistas em periódicos e rádios locais);

4) Aplicação do programa de sensibilização turística por meio de palestras destinadas à comunidade local. 
Numa etapa preliminar exploratória, a pesquisa preocupou-se em consultar os moradores locais a fim de obter sugestões sobre os procedimentos e a forma de abordagem a serem adotados para a realização das ações pretendidas e para a viabilização dos objetivos propostos.

A consulta à sociedade local, com a consideração de suas idéias e sugestões (sobre a programação, os procedimentos, métodos, técnicas, e cronograma) foi essencial para que as ações propostas no projeto se desenvolvessem de maneira satisfatória, produtiva e com sucesso.

\subsection{Identificação do perfil socioeconômico e cultural da população local (entrevistas com a população local)}

A pesquisa com moradores locais permitiu a identificação de aspectos do seu perfil socioeconômico e cultural, indispensáveis para a definição do programa de sensibilização turística, e também foi importante para identificar o seu grau de conhecimento sobre a atividade turística.

Além disso, os resultados deste levantamento auxiliaram na definição e elaboração do programa de sensibilização turística mais adequado e adaptado às condições da vida cotidiana da população local, em função das suas características culturais e sociais.

Como os atores locais envolvidos com o turismo foram motivados para a discussão e reflexão sobre o processo de desenvolvimento turístico na região, o trabalho também buscou investigar e caracterizar a expectativa e o interesse da comunidade local no desenvolvimento turístico.

A pesquisa foi realizada por meio de entrevistas diretas aos moradores locais, sendo aplicado questionário semi-estruturado, para levantamento dos seguintes aspectos:

- Perfil socioeconômico cultural;

- Grau de interesse em participação e envolvimento no desenvolvimento do turismo;

- Conhecimento sobre o turismo e seus princípios sustentáveis; os benefícios do turismo; os impactos do turismo;

- Expectativa do desenvolvimento do turismo na região;

- Grau de envolvimento e participação no processo de desenvolvimento turístico. 
As entrevistas individuais com os moradores locais foram realizadas por uma equipe de investigação em campo, composta por colaboradores voluntários e por alunos de graduação dos cursos de Turismo, Geografia e Engenharia Ambiental (Universidade de São Paulo, Escola de Engenharia de São Carlos, Universidade Estadual de Londrina, Centro Universitário de Rio Preto). A formação de uma equipe de campo com vários integrantes teve intuito de agilizar as ações da pesquisa na coleta de dados e entrevistas.

Devido à importância de se obter relatos e dados sinceros dos entrevistados (moradores locais, proprietários rurais e visitantes), buscou-se estudar as técnicas para deixá-los à vontade em responder as questões, e as formas de conquistar a confiança.

Para o treinamento da equipe de campo e para avaliar a fidedignidade e validade dos questionários, foi prevista a realização de pré-testes. Os pré-testes foram realizados por meio da aplicação dos questionários em entrevistas, que foram aprimorados com a finalidade de testar e verificar o entendimento, a pertinência e a completitude das questões.

A pesquisa realizou entrevistas com 65 moradores locais, produtores e proprietários rurais, cujos resultados propiciaram a identificação do seu pefil socioeconômico e cultural, e também o reconhecimento do seu interesse e compreensão sobre o turismo.

O levantamento do perfil turístico da sociedade local foi importante para direcionar as estratégias de aplicação dos programas de sensibilização turística facilitando o conteúdo a ser abordado e a linguagem técnica a ser empregada.

O reconhecimento, a valorização e o respeito dos aspectos culturais e comportamentais dos moradores propiciaram a proposição de ações condizentes, pertinentes e aplicáveis à realidade local, que foram balizadas e acreditadas pela comunidade local.

Conforme pode se observar nas Figuras 1 e 2, a maioria dos moradores locais entrevistados possui até o ensino médio completo (apenas 3\% possuem superior incompleto) e recebe renda mensal de até $\mathrm{R} \$ 2.000,00$ (98\%). 
ESCOLARIDADE

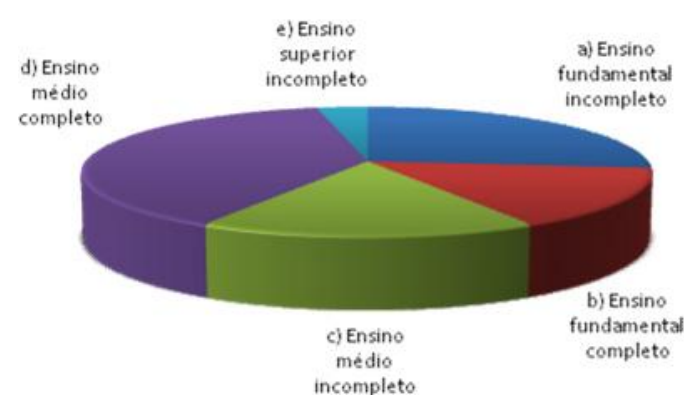

RENDA FAMILIAR

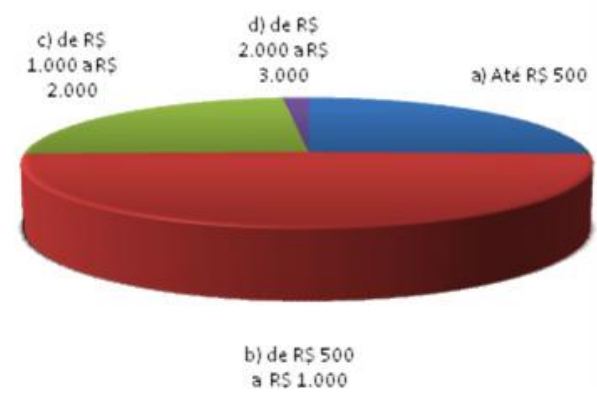

Figuras 1 e 2 - Escolaridades e rendas familiares dos moradores locais entrevistados

A pesquisa com os moradores locais identificou o grau de conhecimento sobre turismo autoatribuído, sendo que $82 \%$ se consideram pouco informados e $18 \%$ se consideram totalmente desinformados sobre turismo. Entretanto, observou-se o interesse e a disposição favorável dos moradores locais em obter conhecimentos sobre a atividade turística, sendo que $82 \%$ dos entrevistados se mostraram dispostos a participar das reuniões e palestras de sensibilização turística (Figuras 3 e 4).

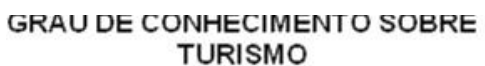
TURISMO

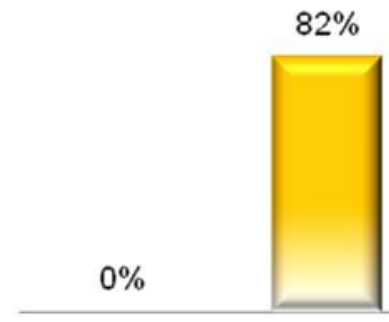
a) Bastante
b) Pouco
c) Nada
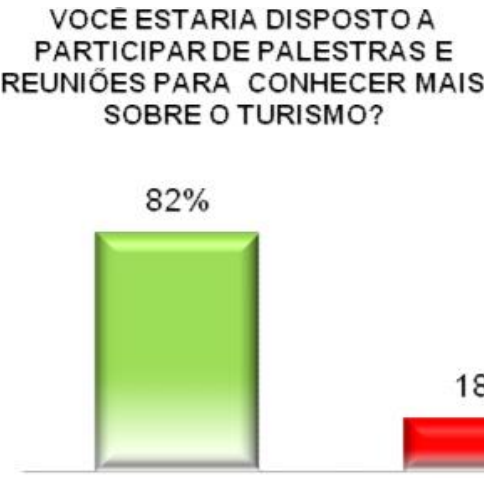

a) $\operatorname{Sim}$
$18 \%$

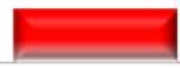

b) Não

Figuras 3 e 4 - Grau de conhecimento dos moradores locais sobre turismo e sua disposição em participar de palestras e reuniões de sensibilização turística 
Observa-se pelas Figuras de 5 a 8 , o desconhecimento dos moradores locais sobre os possíveis efeitos das atividades turísticas num destino, pois: 54\% dos moradores entrevistados acreditam que não existam problemas e impactos negativos advindos do turismo; a maioria (86\%) deles considera o número grande de visitantes apenas do ponto de vista benéfico; apenas $45 \%$ acham que o desenvolvimento do turismo pode danificar a natureza; e $79 \%$ não acham que o turismo modifica os hábitos e os costumes culturais locais.
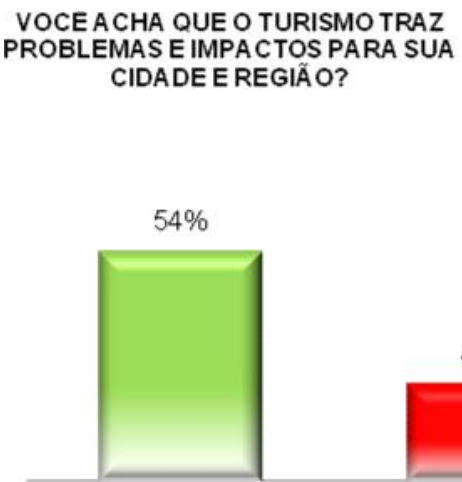

a) Sim

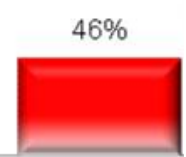

b) Năo

VOCE ACHA QUE O DESENVOLVIMENTODO TURISMO PODE DANIFICAR A NA TUREZA?

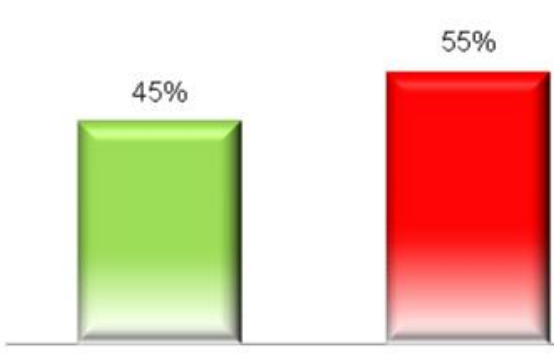

a) Sim

b) Não

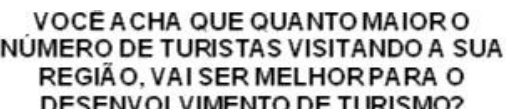

DESENVOLVIMENTO DE TURISMO?

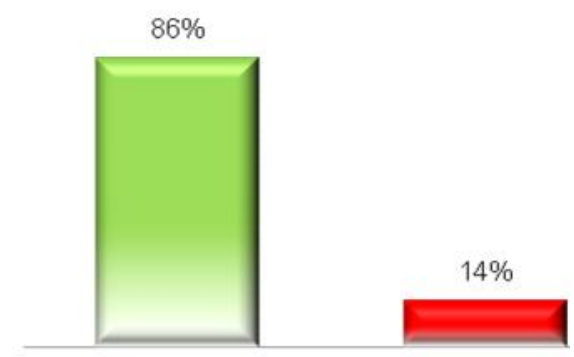

a) Sim

b) Não
VOCE ACHA QUE O DESENVOLVIMENTO DO HABITOS?

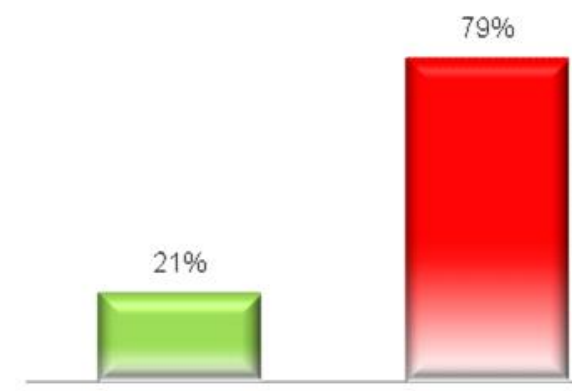

a) Sim

b) Năo

Figuras $-5,6,7$ e 8 -Conhecimento dos moradores locais sobre os efeitos do desenvolvimento do turismo 
Esta constatação reforça a necessidade da elaboração e aplicação do programa de sensibilização sustentável do turismo destinado aos moradores locais, visando maior esclarecimento sobre o desenvolvimento da atividade turística e seus efeitos num destino.

\subsection{Preparação do conteúdo e elaboração de materiais didáticos e informativos para o programa de sensibilização turística}

O conteúdo selecionado para a aplicação do programa de sensibilização turística envolveu os seguintes assuntos fundamentais sobre desenvolvimento do turismo sustentável: os conceitos básicos de turismo, ecoturismo, turismo rural; princípios do turismo sustentável; a elaboração de um produto turístico; a importância da diversidade de produtos turísticos; a importância da satisfação do turista e a imagem de um local turístico; a divulgação de um destino turístico; exigências de um produto turístico; os impactos do turismo; o "ciclo de vida" de um destino turístico; o planejamento e a organização do turismo sustentável; organização, envolvimento e participação turística; estrutura de gestão do turismo e do conselho municipal de turismo.

Materiais didáticos (cartilha ${ }^{4}$ e apostila) foram preparados, publicados e disponibilizados para apoio ao programa de sensibilização sustentável do turismo, constituindo-se em meios alternativos e adicionais de comunicação, que auxiliaram, reforçaram e complementaram a aprendizagem dos assuntos abordados.

\subsection{Aplicação do programa de sensibilização turística em meios de comunicação (spots para veiculação em rádios, entrevistas em periódicos e rádios locais)}

No caso específico dos municípios do sul do estado de Minas Gerais, devido às características de cidades de pequeno porte e de cultura predominantemente rural, as emissoras de rádio e os jornais locais constituem-se em importantes e abrangentes meios de comunicação, pois possuem grande audiência, repercussão e aceitação.

Assim, as estratégias de aplicação do programa de sensibilização turística foram definidas em função das características locais e das condições disponíveis para implementação do programa, envolvendo os seguintes meios de comunicação:

\footnotetext{
${ }^{4}$ A cartilha com o título "Conscientização Sustentável do Turismo" aborda os principais assuntos relacionados ao desenvolvimento sustentável do turismo, em linguagem simples, acessível e ilustrativa (HANAI; ESPÍNDOLA, 2007).
} 
- os spots em rádios (mensagens curtas e instantâneas para a informação de um tema específico, no caso sobre o desenvolvimento sustentável do turismo), veiculados em emissoras locais dos municípios;

- as entrevistas concedidas em rádios locais, abordando as ações do projeto e os princípios do desenvolvimento do turismo sustentável;

- as matérias e artigos redigidos sobre as ações e programação do projeto, publicados nos periódicos e jornais da região.

A elaboração e veiculação dos spots em rádios envolveram os seguintes procedimentos: a seleção dos conteúdos mais relevantes e possíveis de serem transmitidos via oral; a definição da sequência apresentada dos conteúdos; a gravação dos spots em estúdio fonográfico; a edição e preparação dos spots; a distribuição dos spots nas principais rádios da região; e a veiculação periódica.

Os seguintes temas e mensagens foram abordados nos spots em rádios: conceituação de turismo; ecoturismo; turismo rural; a importância do atendimento e receptividade do turista; os benefícios do turismo; a dependência do turismo nos atrativos naturais conservados; a importância da valorização e preservação dos patrimônios históricos e culturais; os desafios da sazonalidade do turismo; os resultados do turismo a médio e longo prazos 5 ; a importância do envolvimento e da participação da população no planejamento e desenvolvimento do turismo; o planejamento do turismo numa propriedade rural; e temas variados do tipo "você sabia?".

As entrevistas em rádios e as matérias publicadas nos jornais locais ocorreram durante o desenvolvimento das ações nos municípios, e permitiram também uma maior divulgação da programação das ações e das palestras de sensibilização turística (datas, horários e locais de realização).

\footnotetext{
${ }^{5}$ A população local deve estar consciente de que planos e projetos de turismo imediatistas, que visam o rápido desencadeamento de atividades turísticas em massa, podem causar impactos negativos, como a descaracterização do ambiente, degradação dos patrimônios naturais e culturais. Os benefícios são momentâneos, duram pouco tempo e tem repercursão isolada, e não coletiva.
} 


\subsection{Aplicação do programa de sensibilização turística por meio de palestras destinadas à comunidade local}

As palestras de sensibilização turística foram programadas, organizadas e promovidas conjuntamente com o envolvimento de colaboradores dos municípios (gestores, guias, líderes locais), considerando-se as facilidades existentes e as orientações e sugestões advindas destes colaboradores para melhor adequação do programa de sensibilização turística às disponibilidades, conveniências e comodidades da sociedade local.

Foram convidados para as palestras e reuniões técnicas, os administradores públicos, os empresários do setor turístico, os guias locais, proprietários e gerentes de agências receptivas, os comerciantes e os moradores locais (público geral), para explanação das bases e conceitos primordiais do desenvolvimento turístico sustentável.

A realização das palestras contou com o apoio e a parceria da gestão pública local (secretarias e diretorias de turismo e meio ambiente das prefeituras municipais), gestores turísticos, empresários e envolvidos no setor turístico, e também dos veículos de comunicação (jornais e rádios locais).

\section{Resultados e Recomendações do Programa de Sensibilização Turística}

Doze reportagens em periódicos locais foram publicadas e mais de 160 inserções dos spots em rádios foram veiculados durante a aplicação do programa de sensibilização turística, atingindo uma população de aproximadamente 150.000 habitantes pela abrangência das emissoras (dados estimados pela Assessoria de Comunicação).

Foram promovidas e realizadas oito palestras e vinte e oito reuniões técnicas com a participação de empresários, dirigentes, gestores públicos municipais, guias de turismo, comerciários e os residentes locais, envolvendo um total de 216 participantes.

Ao final da realização das palestras, foi aplicado um pequeno questionário aos presentes com o objetivo de avaliar os procedimentos adotados no programa de sensibilização turística.

Os resultados da aplicação das questões apontaram que todos os participantes $(100 \%$ das pessoas que compareceram às palestras) consideraram os assuntos tratados importantes para o desenvolvimento turístico da região, e cerca de $96 \%$ acharam que as palestras aumentaram 
muito o seu conhecimento sobre a sustentabilidade do turismo e a importância de seu planejamento.

A realização das entrevistas com aplicação dos questionamentos sobre os interesses dos moradores locais no turismo (abordados na pesquisa realizada durante as entrevistas) despertaram a sua curiosidade pelo turismo, promovendo o início do processo de conscientização e incitando a sua participação nos programas de sensibilização turística.

Estes resultados demonstram a importância e reforçam a necessidade da realização e valorização dos programas de sensibilização e educação turísticas nos destinos turísticos, envolvendo não somente os gestores, empresários, dirigentes e atores sociais atuantes no setor turístico, mas também toda a comunidade local.

A consciência turística dos moradores locais proporcionou também a incorporação de princípios de asssociativismo e cooperativismo, que incentivam a formação de associações com fins sociais, coletivos e comunitários, indispensáveis para o desenvolvimento local.

A aplicação e implementação do programa de sensibilização turística permitiram a oportunidade de vivenciar experiências metodológicas, com a aquisição e a proposição de recomendações e legados metodológicos advindos desta pesquisa.

Por meio da realização deste estudo no sul do estado de Minas Gerais, observou-se que os programas de sensibilização turística considerem as seguintes recomendações e aspectos relevantes no seu processo de elaboração e desenvolvimento:

Os programas de sensibilização turística devem considerar os pressupostos culturais, ideológicos ou religiosos da comunidade, sem os quais resulta ser praticamente impossível a efetivação e concretização das ações propostas. A consideração de valores culturais da comunidade constitui-se num aspecto de extrema importância para a definição da abordagem, conteúdo e estratégias de aplicação de um programa de sensibilização turística;

$>$ A programação das estratégias de sensibilização turística deve ser realizada conjuntamente com gestores locais a fim de conciliar as ações programadas com as atividades cotidianas e rotineiras da comunidade;

$>\quad$ Os termos técnicos específicos sobre turismo e sustentabilidade devem ser adaptados à uma linguagem simples, usual e compreensível pela população local; 
- Os fatos e as situações cotidianas da realidade do local devem ser inseridos para exemplificação dos conceitos e conteúdos do turismo. Para isso é necessário um levantamento prévio das características turísticas locais (atrativos naturais, culturais, históricos locais), que possibilitam a melhor compreensão das mensagens a serem transmitidas;

$>\quad$ Os programas de sensibilização turística não devem possuir o caráter de um curso de capacitação e desta forma, técnicas e materiais didáticos de interpretação gráfica, dinâmicas, práticas pedagógicas, cursos, palestras, eventos devem ser desenvolvidos para implementação do programa, assim como outros meios alternativos e inovadores de comunicação e de alcance público;

$>\quad$ O levantamento preliminar, por meio de entrevistas e aplicação de questionários, do grau de conhecimento da população local sobre o turismo é importante para a definição dos conteúdos e estratégias do programa de sensibilização turística, assim como a posterior avaliação de seu desempenho;

> Os programas de sensibilização turística devem contemplar também a sua autoavaliação, a fim de verificar se os procedimentos adotados tem propiciado uma evolução na consciência turística da população local.

Os programas de sensibilização turística não devem se constituir em meios de convencimento passivo da população local ou de legitimação dos diversos interesses (nem sempre coletivos) ou de imposições do desenvolvimento irrestrito do turismo numa localidade.

Na sensibilização turística é necessária muita cautela para não gerar falsas expectativas e ilusões na população local. Os programas de sensibilização turística devem propiciar a elucidação da população local sobre as oportunidades e também sobre os possíveis riscos associados ao desenvolvimento do turismo, no sentido de considerá-lo como alternativa (não a única opção ideal) de desenvolvimento local.

Além disso, deve-se enfatizar a ideia de que o turismo é uma alternativa econômica cujos efeitos são percebidos a médio e a longo prazos, pois trata-se de uma atividade sazonal que depende de diversas condições externas a localidade. 


\section{Considerações Finais e Conclusões}

O esforço em sensibilização da sociedade para o turismo sustentável é primordial para a construção de novos paradigmas do desenvolvimento turístico, em que se incorpora a efetiva participação das comunidades anfitriãs no processo de planejamento e organização do turismo.

A sensibilização turística propicia oportunidades de atuação ativa da comunidade local em processos decisórios, propiciada pelo esclarecimento, compreensão e incorporação de conhecimentos básicos sobre os fenômenos associados à atividade turística, permitindo a consciência para a definição de rumos desejáveis e direcionamento do processo de desenvolvimento do turismo e da sociedade local.

Neste estudo de caso de aplicação do programa de sensibilização turística no sul do estado de Minas Gerais, o empenho da sensibilização da comunidade local para o turismo sustentável foi essencial para a construção de novos paradigmas de desenvolvimento turístico, valorizando a identidade e os interesses comunitários regionais.

A sensibilização turística ressaltou a importância da inserção e atuação da população local no processo de desenvolvimento turístico, apontando a grande responsabilidade atribuída aos moradores locais, que são importantes atores sociais e dinâmicos para o sucesso do desenvolvimento turístico sustentável.

As comunidades anfitriãs, esclarecidas e conscientes, puderam participar, se envolver e colaborar de maneira ativa e efetiva nos processos de planejamento, organização e desenvolvimento do turismo.

O programa de sensibilização turística promoveu aos residentes locais a elucidação das necessidades, prioridades e aspectos essenciais do planejamento e desenvolvimento do turismo regional.

A sensibilização da população local sobre a sustentabilidade do turismo permitiu: aumentar sua capacidade de participação e de organização (adquirindo novas habilidades); fortalecer sua capacidade de argumentação e de posicionamento de forma crítica frente a outros interlocutores; e potencializar sua atuação de forma conjunta e integrada para o desenvolvimento local do turismo sustentável. 


\section{Referências}

BOOTHROYD, P. Enhancing local planning skills for native self-reliance: the UBC experience. The Canadian Journal of Native Studies, Brandon, n.4, v.1, p.13-42, 1986.

BRASIL. Ministério do Turismo. Programa de regionalização do turismo: roteiros do Brasil. Brasília, DF: Ministério do Turismo, 2004a. 32 p.

BRASIL. Ministério do Turismo. Diretrizes operacionais do programa de regionalização do turismo: roteiros do Brasil. Brasília, DF: Ministério do Turismo, Secretaria Nacional de Políticas de Turismo, 2004b. 61p.

BRASIL. Ministério do Turismo. Módulo operacional 1 - sensibilização do programa de regionalização do turismo: roteiros do Brasil. Brasília, DF: Ministério do Turismo; Secretaria Nacional de Políticas de Turismo; Departamento de Estruturação, Articulação e Ordenamento Turístico; Coordenação Geral de Regionalização, 2007. 75 p.

CHOI, H.C.; SIRAKAYA, E. Measuring residents' attitude toward Sustainable Tourism: development of sustainable tourism attitude scale. Journal of Travel Research, Sage Publications, Thousand Oaks, v.43,p.380-394, may 2005.

CHOI, H.C.; SIRAKAYA, E. Sustainability indicators for managing community tourism. Tourism Management, Elsevier, London, v.27, p.1274-1289, dec. 2006.

CONFERÊNCIA MUNDIAL DE TURISMO SOSTENIBLE, 1., Lanzarote, Ilhas Canarias, Espanha. Carta del Turismo Sostenible... Lanzarote, Ilhas Canarias, Espanha: [s.n.], 1995. p.1-5.

IRVING, M.A.; BURSZTYN, I.; SANCHO, A.P.; MELO, G.M. Revisitando significados em sustentabilidade no planejamento turístico. Caderno Virtual de Turismo, Instituto Virtual de Turismo, Rio de Janeiro, n.18, dez. 2005. p.1-7.

KO, T.G. Development of a tourism sustainability assessment procedure: a conceptual approach. Tourism Management, Elsevier, London, n.26, p.431-445, 2005.

MARTÍNEZ, A.J.J.; HIRABAYASHI, Y. De la teoría a la práctica em la sustentabilidad y la participación comunitaria: na propuesta metodológica. In: NIEVES, S.G. Desarrollo turístico y sustentabilidad. Zapopan, Jalisco: Universidad de Guadalajara, 2003. p. 37-56.

McCOOL, S.F.; MOISEY, R.N.; NICKERSON, N.P. What should tourism sustain? The disconnect with industry perceptions of useful indicators. Journal of Travel Research, Sage Publications, Thousand Oaks, v.40, n.2, p.124-131, nov.2001.

OLIVEIRA, C.G.S. Viabilidade e sustentabilidade do turismo rural. Brasília, DF: Serviço Nacional de Aprendizagem do Cooperativismo, 2002.

ORGANIZAÇÃO MUNDIAL DE TURISMO. Guia de desenvolvimento do turismo sustentável. Tradução de Sandra Netz. Porto Alegre: Bookman, 2003. 168p.

PETERSEN, P.; ROMANO, J.O. Abordagens participativas para o desenvolvimento local. Rio de Janeiro: AS-PTA/Actionaid Brasil, 1999. 144p.

RANAURO, M.L. Sustentabilidade numa perspectiva endógena: contribuição das "comunidades" no plano simbólico do desenvolvimento sustentável. Caderno Virtual de Turismo, Rio de Janeiro, n.14, p.21-28, dez. 2004.

SÁNCHEZ RIVERO, M.; PULIDO FERNÁNDEZ, J.I. Medida de la sostenibilidad turística: propuesta de un índice sintético basado en ponderaciones factoriales. Madrid: IX CONVOCATÓRIA PREMIO TRIBUNA FITUR JORGE VILA FRADERA 2007; FITUR, 2008. 203p. 
SWARBROOKE, J. Turismo Sustentável: conceitos e impacto ambiental. São Paulo: Aleph, 2000. 140p.

YUNIS, E. Indicadores de turismo sostenible: o enfoque de la OMT. In: SEMINÁRIO INTERNACIONAL INDICADORES AMBIENTALES DE TURISMO, 2002, Murcia (España). Informe... Murcia (España): Mullor y Asociados, 2002, p.11 - 13.

Recebido em: 17/12/2009 (1 ${ }^{\mathrm{a}}$ versão) $12 / 11 / 2010$ ( $2^{\mathrm{a}}$ versão)

Aprovado em: 14/03/2011 